\title{
Patent Pool Formation and Scope of Patents
}

\author{
Corinne Langinier*
}

September 2007

\begin{abstract}
Basic innovations are often fundamental to the development of applications that may be developed by other innovators. In this setting, we investigate whether patent pools can rectify the lack of incentives for a developer to invest in an application. Following Green and Scotchmer (1995), we also wonder whether broad basic patents are necessary in order to provide enough incentives for basic innovators. We show that patent pools are more likely to be formed with patents of very different breadths, or patents of similarly wide breadths. Further, although patent pools rectify the problem of developer incentives, they may reduce the incentive for doing basic research.
\end{abstract}

Keywords: Patent pool, innovation, breadth

JEL classification: K11, L4, O31

*Iowa State University, Ames. Tel: (515) 294-5830; Fax: (515) 294-0221 langinier@econ.iastate.edu I am indebted to comments from Philippe Marcoul, Jorge Andres Ferrando Yanez and other participants at the IIOC 2004 in Chicago. 


\section{Introduction}

In some areas of research (e.g., biotechnology), follow-up innovations may be built on several basic innovations, and might not be developed without them. Inventions such as methods to isolate and locate gene sequences have no value by themselves, but they permit the development of subsequent valuable applications. Furthermore, basic innovations and applications are usually developed by different companies. ${ }^{1}$

Two important incentive problems emerge from sequential innovations. First, basic innovators must be given enough incentive to promote their innovations. The literature on sequential innovation has mainly focused on how to protect the first generation of innovators against future innovators. In other words, it is concerned with the transfer of profit from second generation innovators to the initial innovators in order to promote basic innovations (Scotchmer, 1996; Green and Scotchmer, 1995; Chang, 1995). First generation innovators should be given broad protection when second generation innovations can only be obtained by an outsider (Green and Scotchmer, 1995). ${ }^{2}$

Second, follow-up innovations may not be brought about when developers decide not to pursue research if it is built on several basic innovations (Merges and Nelson, 1994). Indeed, if basic patents are too broad, follow-up innovators may have to pay too many fees to be able to develop applications. This phenomenon, referred to by Heller and Eisenberg (1998) as the "tragedy of anticommon," depicts a situation in which there are too many door keepers, and to build on previous innovations an innovator needs the permission of too many patentholders (Shapiro, 2001). This second problem is specially acute in biotechnology. For instance, a survey of laboratory physicians shows that because of patents one fourth have abandoned a clinical test that they have developed, and almost one half report that they have not developed a test for fear that they would be sued. ${ }^{3}$

In biotechnology, and more generally in fields where innovation is cumulative and pyramidal,

\footnotetext{
${ }^{1}$ For instance, a public laboratory or a research department at a university can develop basic innovations, while letting the private sector develops applications.

${ }^{2}$ In the case of a long sequence of innovation, the optimal scope of patents is provided to stimulate R\&D investment (O'Donoghue, Scotchmer and Thisse, 1998).

${ }^{3}$ This survey has been conducted by Jon Merz and Mildred Cho, bioethicists at the University of Pennsylvania, and has been reported by Thompson, Washington Monthly, April 2001.
} 
one of the solutions is to license patents in a patent pool. A patent pool is an agreement between two or more patentholders to license one or more of their patents to one another or to third parties (Merges, 1999).

In this paper, we examine how a patent pool can rectify the lack of developer incentives to invest in an application when basic innovators cannot develop follow-up applications. This situation is relatively common, as basic innovators may be universities or public research laboratories that do not have the ability to develop applications. We investigate whether broad basic patents are necessary in order to provide enough incentive to basic innovators, as is the case in the Green and Scotchmer (1995) model. Further, we wonder what kind of pool will emerge. In other words, are patents more likely to be broad or narrow in a patent pool? We consider a model in which there are two patentholders of basic innovations that are mainly research tools, with null market values, but that permit a third firm to develop an application. In this setting, we show that patent pools are more likely to be formed either with patents of very different breadth or, on the contrary, with similarly broad patents.

In 2001, several companies (GE Healthcare, formerly Amersham Biosciences, Biolmage A/S and Invitrogen IP Holdings, formerly Aurora Biosciences Corporation) and Colombia University agreed to pool several of their patents on green fluorescent protein (GFP). This is a fluorescent reporter molecule used in drug discovery to create a detailed picture of how potential drugs affect the function of protein. The patent pool contains several U.S. patents, as well as European and Japanese patents. "All users of GFP are required to obtain a license to use the technology prior to starting research work" (GE Healthcare conditions for licensing). ${ }^{4}$ Therefore, one can consider a patent pool as an ex ante agreement offered to any potential developers. The application areas include research in cell biology and pharmaceutical screening. Using Lerner's proxy of the scope of patents, i.e., the number of the first four digits of the International Patent Classification (IPC) in each patent, we find that the patents included in the pool tend to be broad. Indeed, according to Lerner's analysis (1994), the number of four-digit IPC classes into which a patent is classified is, on average, 1.68 for biotechnology patents. Among the eleven patents that are in the pool, if we put together those that are continuations of others (two patents, each with two continuations), most have more than two four-digit IPC classes. In fact, only one of them has one four-digit IPC class. This seems to be consistent with our finding that pools are more

\footnotetext{
${ }^{4}$ See the web site http://www.gehealthcare.com.
} 
likely to be formed with broad patents (see Table 1 that summarizes the information about this existing patent pool).

Our analysis is related to the two streams of literature mentioned above: the literature on sequential innovation, especially the paper by Green and Scotchmer (1995), and the more recent literature on patent pools.

In a model with one patentholder of a basic innovation and one potential innovator to develop the application, Green and Scotchmer (1995) show that an ex ante agreement should be allowed in order to insure investment in the second innovation. When there is no uncertainty about the value of the follow-up innovation, the best policy consists in giving a broad patent to the first innovator, and the ex ante licensing improves social welfare whatever the patent breadth. ${ }^{5}$ However, if the developers' costs are private knowledge, patentholders do not necessarily offer ex ante licensing (Bessen, 2004). We built upon the model of Green and Scotchmer (1995) to investigate patent pools. We explicitly introduce patent breadth, and we extend their analysis to two basic patents that can be pooled in an ex ante agreement in a model where there is common knowledge about costs. The main objective of the Green and Scotchmer (1995) model is to study patent policy and to determine what the optimal patent breadth should be. In our setting, we show how given patent breadths impact the choice of whether or not to form a patent pool. Therefore, our focus is on strategic choices by firms to form a patent pool as a function of patent breadth.

Patent pools are viewed as a possible solution for reducing additional transaction costs incurred in navigating the patent thicket (Shapiro, 2001) or the anticommon problem (Heller and Eisenberg, 1998; Buchanan and Yoon, 2000). They can also enhance efficiency by eliminating the complement problem (Shapiro, 2001), and may benefit society (Gilbert, 2004; Lerner and Tirole, 2004; Gilbert and Katz, 2006). Following Cournot analysis, Shapiro (2001) shows that a package of licenses for basic innovations neither harms consumers nor the firms themselves, as long as the royalty rates are low.

\footnotetext{
${ }^{5}$ If there is competition at the level of development, Scotchmer (1996) shows that patents on second generation products (when they infringe on the first innovation) are not necessary to encourage their development, and the patentholder of the basic innovation collects a larger share of the profit if second generation products are not patentable. On the other hand, if competition can take place at both research and development stages, and if both stages can be done by the same firm, Denicolo (2000) shows that weak forward protection can be preferable.
} 
The major benefits of patent pools are that they eliminate staking licensing, reduce licensing transaction costs, reduce patent litigation and allow for the exchange of information. However, a patent pool can have anti-competitive effects. Antitrust authorities have been consistently more suspicious of a pool of substitutable patents than of a pool of complementary patents. If patents are perfect complements, a pool eliminates the double marginalization (Shapiro, 2001). If they are perfect substitutes, a pool eliminates competitors. However, patents are rarely perfect complements or perfect substitutes. In this context, Lerner and Tirole (2004) study a model of pool formation and pricing, and show that a pool can increase or decrease the price, depending on the internal or external competition. Further, large pools are more likely to allow individual licensing, to centralize control of litigation and to license to third parties (Lerner, Strojwas and Tirole, 2003). In our model, we consider that a patent pool is an ex ante agreement where patents are complements, as both innovations are needed to develop the application. In this setting, we wonder what breadths of patents are more likely to be pooled together.

In most of the literature on patent pools, it is assumed that firms do participate in the pool (e.g., Lerner and Tirole, 2004). However, joining a pool is a voluntary decision and, therefore, firms may decide not to join a patent pool. In the setting of a consortium standard, Aoki and Nagoaka (2004) analyze the decision of a firm not to join a patent pool, or the reasons for the split of a patent pool. They show that because of free-riding and bargaining failures (due to heterogenous firms), firms do not always want to be part of a patent pool. In our setting, our findings are similar: when firms are heterogenous (in terms of patent breadths), a patent pool can fail. However, in the extreme case, when firms have patents of very different breadth, we find that a pool will be formed. The apparent contradiction in our findings is due to the different modelling framework. Indeed, in their model, implicitly ex post efficiency is always achieved, whereas we do account for situations in which the application will not be developed. From an empirical standpoint, Layne-Farrar and Lerner (2006) provide an analysis to test the determinants of joining a pool. One of their findings is that firms with relatively symmetric contributions to a new technology are more likely to form a patent pool. This seems to be consistent with one of our main findings, that firms with broad patents are more likely to form a pool. Our paper is a contribution to this new stream of literature on patent pools that is related to the voluntary aspect of joining a patent pool. In a setting where the scope of patents is accounted for, we study the incentives to join a pool and analyze the formation of patent 
pools as a function of the breadth of patents.

The paper is organized as follows. In section 2 we present the model, based on Green and Scotchmer (1995). Section 3 is devoted to the resolution of the game. We first present a benchmark case in which only one basic innovator holds a patent. Then we consider the richer case, where two basic innovations are owned by two different patentholders, and we determine the composition of the patent pool. In section 4, two extensions are provided. Section 5 concludes.

\section{The Model}

We consider a modified version of the Green and Scotchmer (1995) model (hereafter, GS), in which two initial innovators, firms 1 and 2, each hold a patent on a basic innovation. The associated (sunk) costs for discovering each basic innovation are $c_{1}$ and $c_{2}$. Each protected innovation has no value by itself, but is indispensable in developing an application. In other words, even if its value is null, its value-added quality is very important to the application's development. For instance, it could be genes that may be useful in the development of a certain medicine. ${ }^{6}$

We assume that the initial innovators are unable to develop a second generation of product (an application that uses the patented innovations) as, for instance, they specialize in fundamental research rather than in development. In this setting, the application must be developed by another firm, say firm $A$, that does not hold the basic innovations and, further, we assume that it can be developed by only one firm. The application has a monopoly value $v$ and cost $c_{a}$ of development. If it infringes upon the patented innovations, the application can only be introduced on the market if an agreement has been reached with the patentholders and, thus, its value $v$ is to be shared with the initial innovators. If the application does not infringe, the value $v$ is the developer's alone. There is no uncertainty concerning the future value of the application. ${ }^{7}$

\footnotetext{
${ }^{6}$ For instance, a combination of several research tools (the PCR enzyme for replicating DNA, technologies for inserting foreign genes into germplasms, technologies for making those genes produce proteins,...) has been used to develop a version of Bt corn, i.e., corn seeds that code for and "express" (i.e., produce protein for) a particular kind of pest resistance.

${ }^{7} \mathrm{~A}$ more realistic approach, and more complicated, should take into account the fact that the value of the application is uncertain.
} 
The scope of protection (i.e., breadth) that each of the initial innovators obtains for his innovation can be narrow, broad or anything in between. In the extreme case of patents of infinite breadth, the application always infringes upon the patented basic innovations. In the other polar case, if the breadth of the patent is null, the application never infringes. More generally, the breadth of a patent is related to the ex ante probability of infringing and, as such, we define the breadth as being exactly the probability of infringing. With probability $b_{i} \in(0,1)$ the application infringes upon the patent of firm $i$ for $i=1,2$, and with probability $\left(1-b_{i}\right)$ it does not. We do not define a priori which patent is broader than the other. We consider that both patented innovations are indispensable to the development of the application or, in other words, that the patents are complements. Therefore, ex ante, there is a probabilistic infringement, and the application has some probability of infringing upon both patents.

Two kinds of agreements can be reached between the developer and the initial innovators: an ex ante agreement - before the investment in the development has been undertaken - or an ex post agreement - after the investment in the development occurs in the case of infringement.

At the outset of the game, both patentholders simultaneously decide whether or not to pool their patents. If they both decide to pool, they propose an ex ante agreement (patent pool) to the developer who refuses or accepts it. If one of the patentholders agrees to pool and the other refuses, no pool is offered. However, we assume that the patentholder who wanted to be part of a pool offers an ex ante agreement to the developer, ${ }^{8}$ who accepts or refuses it. Then the developer must decide whether to invest in the development of the application or not (see the tree of the game).

If no ex ante agreement is offered, or if the developer refuses it and still invests in the development, following GS (1995) we assume that the parties achieve ex post efficiency. In other words, in absence of an ex ante agreement, the developer and the basic innovators must agree on ex post licensing if the application infringes on the basic patents.

The structure of the payoffs is detailed in the next section, before the resolution of the game in cases where there are one and two innovators. To simplify we normalize the discount factor to be one.

\footnotetext{
${ }^{8}$ Alternatively, and probably more realistically, we could assume that in the case of a patent pool failure, both firms are free to offer an ex ante agreement to the developer. Qualitatively, it does not change our findings, as explained in section 4 .
} 
Insert tree here

To summarize, the timing of the game goes as follows.

- First, both basic innovators decide simultaneously to form a patent pool or not. If they form a pool, they offer an ex ante agreement to the developer. If a pool fails to form, one of the patentholders may still offer an ex ante agreement.

- Second, no matter what ex ante agreement is offered, the developer accepts or refuses it and decides whether or not to invest in the development of the application.

- Third, if the developer has invested, depending on the chosen agreement, firms earn payoffs. In the absence of ex ante agreement, ex post efficiency is achieved if infringement occurs.

\section{Resolution of the Game and Patent Pools}

In order to solve for the game, we first explore the simpler case in which there exists only one patentholder. Then we turn to the richer case of two patentholders.

\subsection{Benchmark case: one basic innovation}

As a benchmark, we consider that only one initial innovator, say firm 1, holds a patent. At best, if he were to develop the application as well, he would invest in the application if $v-c_{a}>0$. However, only firm $A$ can develop the application.

In the absence of any ex ante agreement, the developer and the basic innovator must agree on ex post licensing if the application infringes upon the basic patent. Without such an ex post agreement, the application cannot be introduced to the market; the patentholder earns $-c_{1}$ and the developer $-c_{a}$ if he has invested, or 0 if he has not. However, once the developer has invested, if both firms reach an ex post agreement, firm 1 earns $-c_{1}+K_{1} v$ and firm $A,-c_{a}+\left(1-K_{1}\right) v$, where $K_{1}$ represents the fraction of the gain that goes to the first innovator.

Nonetheless, the probability of infringing upon the basic innovation is $b_{1}$ and, therefore, in order to decide to invest, the developer must compare his expected payoff from investing, $b_{1}\left(-c_{a}+\left(1-K_{1}\right) v\right)+\left(1-b_{1}\right)\left(-c_{a}+v\right)=-c_{a}+\left(1-b_{1} K_{1}\right) v$ to 0 . He will invest only if 
$-c_{a}+\left(1-b_{1} K_{1}\right) v>0$, or equivalently $b_{1}<\left(v-c_{a}\right) / K_{1} v$. Therefore, as long as the probability of infringing is high enough, $b_{1}>\left(v-c_{a}\right) / K_{1} v$, there is under-investment in the application.

As we are mainly interested in looking at the case where there is a lack of incentive to develop an application in the case of infringement, we restraint our analysis to certain values of the parameters. We assume that the value of the second generation product $v$ is such that

$$
\begin{gathered}
v-c_{a}-c_{1} \geq 0, \\
v\left(1-K_{i}\right)-c_{a}<0, \\
K_{i} v-c_{i}>0,
\end{gathered}
$$

where $i=1$ in the case of one patentholder. In the next section, we analyze the case of two patentholders and, therefore, $i=1,2$. Assumption (1) states that all of the research would have been undertaken by the initial innovator, had he been able to do so. In other words, the innovation is worthwhile. Assumption (2) implies that in absence of any ex ante agreement, the follow-up application would not be developed in equilibrium. Finally, assumption (3) insures that the basic innovator undertakes the basic research as long as he can get a sufficient share of the payoff in the ex post agreement.

In order to solve the under-investment problem, as in GS (1995), firms can sign an ex ante agreement before the investment in development is undertaken. In GS (1995), firms are engaged in a cooperative simultaneous bargaining game. ${ }^{9}$

Here we depart from the GS model and assume that the patentholder first decides to offer an ex ante agreement to the developer (a "take-it-or-leave-it" offer). If the developer accepts it, the payoff of the patentholder becomes $-c_{1}+k_{1}\left(v-c_{a}\right)$, and the developer, $\left(1-k_{1}\right)\left(v-c_{a}\right)$, where $k_{1}$ is the share of payoff that goes to the patentholder. In fact, this share of payoff is chosen by the patentholder. ${ }^{10}$ The first-mover advantage that results from this sequential bargaining will manifestly push the patentholder to make an offer with $k_{1}$ as large as possible $\left(k_{1}=1-\varepsilon\right.$, with

\footnotetext{
${ }^{9}$ In GS (1995), each of them receives his threat point profit plus one-half of the bargaining surplus. Thus, for each threat-point considered, the firms will get a certain profit that must be at least equal to what they will earn without it.

${ }^{10}$ To simplify, we only focus on strategies that are dichotomic decisions: offer an ex ante agreement or not, accept it or not, and invest in the development or not. Therefore, we do not explicitly define the optimal choices for the share of the payoff.
} 
$\varepsilon$ very small). As such, we further make the following assumption

$$
k_{i}\left(v-c_{a}\right)-c_{i} \geq 0
$$

for $i=1,2$.

The possibility of having an ex ante agreement restores the incentive to invest. Indeed, the investment will take place as long as $\left(1-k_{1}\right)\left(v-c_{a}\right)>0$, even if $b_{1}>\left(v-c_{a}\right) / K_{1} v{ }^{11}$

For any positive value of the breadth $\left(0<b_{1} \leq 1\right)$, whenever an ex ante agreement is offered, firm $A$ always has an incentive to invest in the development of the application. Indeed, for higher values of $b_{1}, b_{1}>\left(v-c_{a}\right) / K_{1} v$, absent of any ex ante agreement, the development would not occur. On the other hand, for values of $b_{1} \leq\left(v-c_{a}\right) / K_{1} v$, even if offered, firm $A$ will never accept an ex ante agreement, and ex post efficiency will be achieved in case of infringement. We summarize this first result as in GS (1995).

Lemma 1 (Incentive to develop) If there is only one basic innovator, ex ante agreement restores the incentive to develop an application.

Nevertheless, ex ante, the patentholder needs to have enough incentive to invest in the basic innovation. In the absence of any ex ante agreement, firm 1 will undertake basic research only if $b_{1} \geq c_{1} / K_{1} v$. On the other hand, in the presence of an ex ante agreement, it will always undertake basic research. Thus, we can posit the following result.

Lemma 2 (basic research) Under assumptions (1)-(4), firm 1 invests ex ante in basic research only if the patent protection is not too narrow (i.e., $b_{1} \geq c_{1} / K_{1} v$ ).

Once firm 1 has enough incentive to invest in basic research, we can summarize whether an ex ante or ex post agreement will take place at the equilibrium in the following proposition.

Proposition 1 (ex ante versus ex post agreements) Under assumptions (1)-(4), and if there is investment in basic research (i.e., $b_{1} \geq c_{1} / K_{1} v$ ),

\footnotetext{
${ }^{11}$ In GS (1995), when the threat-point profit is $-c_{1}$ for the patentholder and 0 for the developer, as is the case when the developer does not invest without an ex ante agreement, the ex ante agreement payoffs become $-c_{1}+\left(v-c_{a}\right) / 2$ for the patentholder and $\left(v-c_{a}\right) / 2$ for the developer. In their formulation, $k_{1}=1 / 2$, as both firms simultaneously agree on a share of profits, and $b_{1}=1$ or $b_{1}=0$.
} 
i. for smaller probabilities of infringement, i.e., $b_{1}<\left(v-c_{a}\right) / K_{1} v$, the equilibrium is such that there is only ex post agreement.

ii. for larger probabilities of infringement, i.e., $b_{1} \geq\left(v-c_{a}\right) / K_{1} v$, the equilibrium is such that there is only ex ante agreement.

For relatively low values of patent breadth $\left(b_{1} \in\left[c_{1} / K_{1} v, k\left(v-c_{a}\right) / K_{1} v\right]\right)$, the subgame perfect Nash equilibrium is such that the patentholder offers an ex ante agreement that firm $A$ refuses, but still invests in the application. In fact, the probability of infringing is relatively small and, therefore, the developer prefers to invest without any ex ante agreement. For intermediate values of patent breadth $\left(b_{1} \in\left[k\left(v-c_{a}\right) / K_{1} v,\left(v-c_{a}\right) / K_{1} v\right]\right)$, the subgame perfect Nash equilibrium is such that firm 1 does not offer any ex ante agreement, and the developer invests. In those cases, if infringement occurs, there is ex post efficiency (point $i$ ). For a broader patent protection $\left(b_{1} \in\left[\left(v-c_{a}\right) / K_{1} v, 1\right]\right)$, the subgame Nash perfect equilibrium is such that the patentholder offers an ex ante agreement that the developer accepts (point $i i) .{ }^{12}$

Note that from a policy standpoint, if the objective of the government is to minimize the monopoly power of the innovator without reducing the incentive to do either fundamental or applied research, the best policy could be to set $b_{1}^{*}=c_{1} / K_{1} v+\varepsilon$. With such patent protection, at the equilibrium, only ex post agreement will occur.

There is an implicit trade-off between length and breadth (for formal analysis of this tradeoff, see Klemperer, 1990). Indeed, if the value of the application $v$ depends on the duration of the patent, and if we assume that the longer the patent, the higher the value of the application, long patents do not need to be broad. There is a trade-off between long and narrow patents, and short and broad patents. Furthermore, as $\partial b_{1}^{*} / \partial K_{1}<0$, the higher the share of the profit that goes to the basic innovator, the narrower the patent protection should be.

If the patent protection is broad (i.e., $\left.b_{1} \geq\left(v-c_{a}\right) / K_{1} v\right)$, the ex ante agreement restores the incentive to develop the application. However, the patent protection does not need to be very broad (i.e., $\left.b_{1}=1\right)$ to give enough incentive to the basic innovator. If $b_{1}=\left(v-c_{a}\right) / K_{1} v$,

\footnotetext{
${ }^{12}$ The sequential bargaining game introduces a decision stage, and the bargaining is no longer the equilibrium solution. Nevertheless, we find, as in the GS (1995) model, that ex ante agreement can restore the decision of the developer to invest, and that the first patentholder cannot capture all of the surplus.
} 
the higher the $K_{1}$, the lower the $b_{1}$. On the other hand, $\partial b_{1} / \partial v>0$, and, thus, the higher the value of the application, the larger the patent breadth.

\subsection{Two Basic Innovations: Infringement or No Infringement}

We now consider two basic patents held by two innovators. We first analyze the two polar cases when the application does and does not infringe on the basic innovations. We then introduce the breadth of the patents.

In the absence of ex ante agreement, or if the developer refuses it, he still has to decide whether to invest or not. If he does not invest, each patentholder receives $-c_{i}$, where $i=1,2$ and the developer has a null payoff. On the other hand, if he invests and the application does not infringe upon the two basic patents, the payoffs are $-c_{i}$ for each patentholder $i=1,2$ and $v-c_{a}$ for the developer. If the application infringes upon both patents, ex post efficiency must be achieved to bring about the application. Each patentholder $i$ gets $-c_{i}+K_{i}^{e} v$ for $i=1,2$ and firm $A$ gets $-c_{a}+\left(1-K_{1}^{e}-K_{2}^{e}\right) v$, where $K_{i}^{e}$ is the fraction of payoff that goes to each patentholder.

In the case of ex ante agreement, a license is signed between firm $A$ and one or both of the initial innovators before firm $A$ invests in the development of the application. Therefore, both the benefit and the development cost are shared by all of the firms in the agreement, i.e., $v-c_{a}$. The ex ante agreement can take different forms. It can be a patent pool when both patentholders decide to put their patents in a common agreement, or it can be an agreement with only one of them when the other one does not offer a license. In the former case (patent pool), each patentholder receives $-c_{i}+k_{i}^{p}\left(v-c_{a}\right)$ for $i=1,2$, and the developer gets $\left(1-k_{1}^{p}-k_{2}^{p}\right)\left(v-c_{a}\right){ }^{13}$ where $k_{i}^{p}$ is the ex ante share of payoff that goes to each patentholder. In the latter case, if only one of the patentholders proposes an ex ante agreement to the developer, the application can still infringe upon the other patent. If it does, ex post licensing is needed to bring about the application. The patentholder that refuses the ex ante agreement, let us say $j$, will bargain over the totality of the gain from the application, namely $v$. Thus, the payoff of $j$ will be $-c_{j}+K_{j} v$ for $j=1,2$ and $j \neq i$, where $K_{j}$ is the fraction of the payoff that goes to the patentholder. The surplus over which firm $i$ and the developer will ex ante bargain is thus $\left(1-K_{j}\right) v-c_{a}$. Therefore,

\footnotetext{
${ }^{13}$ As patentholders decide to propose a pool of patents, they can choose $k^{p}$ such that each patentholder gets $-c_{i}+\frac{1}{2} k^{p}\left(v-c_{a}\right)$, where $k^{p}$ represents the fraction that goes to the pool, and $\left(1-k^{p}\right)\left(v-c_{a}\right)$ to the developer.
} 
the patentholder $i$ gets $-c_{i}+k_{i}\left(\left(1-K_{j}\right) v-c_{a}\right)$ and the developer gets $\left(1-k_{i}\right)\left(\left(1-K_{j}\right) v-c_{a}\right)$.

If the application does not infringe $\left(b_{1}=b_{2}=0\right)$, then depending upon with whom the developer has an ex ante agreement, the payoffs are $-c_{j}$ for the patentholder that does not have an ex ante agreement, $-c_{i}+k_{i}\left(v-c_{a}\right)$ for the patentholder that proposes such an ex ante agreement, and $\left(1-k_{i}\right)\left(v-c_{a}\right)$ for the developer.

If the application always infringes $\left(b_{1}=b_{2}=1\right)$, at best, if both patentholders propose an $e x$ ante agreement, the developer can earn $\left(1-k_{1}^{p}-k_{2}^{p}\right)\left(v-c_{a}\right)$. However, if only one patentholder decides to propose an ex ante agreement, the developer will get $\left(1-k_{i}\right)\left(\left(1-K_{j}\right) v-c_{a}\right)$.

In the absence of any ex ante agreement, the developer will not invest if $-c_{a}+\left(1-K_{1}^{e}-\right.$ $\left.K_{2}^{e}\right) v<0$, even if $v-c_{a}>0$. Therefore, the same under-investment problem arises with two patentholders. However, this problem can also be solved if ex ante agreements can be reached. When a pool is offered and accepted, the developer always invests, as $\left(1-k_{1}^{p}-k_{2}^{p}\right)\left(v-c_{a}\right)>0$. If only one firm offers an ex ante agreement and there is no infringement, the developer also always invests, as $\left(1-k_{i}\right)\left(v-c_{a}\right)>0$. However, if there is infringement, ex post efficiency must be achieved and, therefore, the developer will invest only if $\left(1-k_{i}\right)\left(\left(1-K_{j}\right) v-c_{a}\right)>0$, i.e., less often than in the case with only one patentholder.

As the patentholders choose simultaneously whether or not to pool their patents (and thus, whether to propose an ex ante agreement or not), we find the Nash equilibria that solve the patent pool game. Because we are mainly interested in knowing how firms will behave when the investment is not undertaken in the case of no ex ante agreement, besides the previous assumptions (1) to (4), we assume that

$$
v\left(1-K_{1}^{e}-K_{2}^{e}\right)-c_{a}<0 .
$$

Assumption (5) insures that ex post efficiency will not be achieved in equilibrium if there is always infringement.

We first consider the case in which the application infringes on the two basic patents $\left(b_{1}=\right.$ $b_{2}=1$ ). Whenever the previous assumptions are satisfied, in the absence of a patent pool the developer does not invest and, therefore, each initial innovator incurs a cost $c_{1}$ and $c_{2}$. If a pool is offered, each patentholder gets $-c_{i}+k_{i}^{p}\left(v-c_{a}\right)$. Therefore, the Nash equilibrium is such that a pool is offered. 
However, if assumption (2) is relaxed, there exist two symmetric Nash equilibria. Either patentholder $i$ proposes an ex ante agreement and $j$ does not or, conversely, patentholder $i$ does not propose an ex ante agreement and $j$ does. The developer accepts the agreement. The patentholders are better off if they do not simultaneously propose an ex ante agreement when the application does infringe on the two basic patents. The reason is simply that neither of them wants to be the first to propose an agreement, but they prefer that someone proposes the agreement over having no agreement. If they were to make their decisions sequentially, there would be a first mover advantage. These equilibria preclude the developer from gaining $\left(1-k_{1}^{p}-k_{2}^{p}\right)\left(v-c_{a}\right)$, and he can only gain $\left(1-k_{i}\right)\left(\left(1-K_{j}\right) v-c_{a}\right)$. Thus, the developer gains less without the pool.

If assumption (5) no longer holds, none of the basic innovators choose an ex ante agreement; thus, there is ex post efficiency. Nevertheless, if $\left(1-K_{j}\right) v-c_{a}<0$, a patent pool is the better solution, as otherwise the development will not be undertaken.

We now consider the case in which the application does not infringe upon the two patents $\left(b_{1}=b_{2}=0\right)$. If there is an ex ante agreement with one of the patentholders, the payoffs are $-c_{j}$ for the patentholder who has no ex ante agreement, $-c_{i}+k_{i}\left(v-c_{a}\right)$ for the patentholder in the ex ante agreement, and $\left(1-k_{i}\right)\left(v-c_{a}\right)$ for the developer. The Nash equilibrium is such that if one patentholder believes that the other will propose an ex ante agreement, he will also choose an ex ante agreement, as he compares $-c_{i}+k_{i}\left(v-c_{a}\right)$ to $-c_{i}$. If he anticipates that the other patentholder does not have such agreement, he proposes an ex ante agreement again, as $-c_{i}+k_{i}\left(v-c_{a}\right)>-c_{i}$. Thus, an ex ante agreement is a dominant strategy in the case of non infringement.

We summarize these findings in the following proposition.

Proposition 2 Under assumptions (1)-(5),

- if the application infringes on both patents, there exists a Nash equilibrium in which the two patentholders decide to pool. The developer accepts the ex ante agreement.

- If the application never infringes on either patent, there exists a unique Nash equilibrium in which the two patentholders decide to pool. The developer refuses it and, thus, ex post efficiency is achieved. 


\subsection{Breadth of Patents}

We now consider that the probability of infringing is strictly positive. Recall that $b_{1}$ is the breadth of the patent that belongs to firm 1 and $b_{2}$ is the breadth of the patent that belongs to firm 2.

Without ex ante agreement, if the developer invests he earns $-c_{a}+b_{1} b_{2}\left(1-K_{1}^{e}-K_{2}^{e}\right) v+$ $\left(1-b_{1}\right) b_{2}\left(1-K_{2}\right) v+b_{1}\left(1-b_{2}\right)\left(1-K_{1}\right) v+\left(1-b_{1}\right)\left(1-b_{2}\right) v$ and each patentholder gets $b_{i} b_{j} K_{i}^{e} v+$ $\left(1-b_{j}\right) b_{i} K_{i} v-c_{i}$ for $i=1,2$. Thus, the developer will invest only if $v\left(1-b_{1} K_{1}-b_{2} K_{2}+\right.$ $\left.b_{1} b_{2} \Delta K\right)-c_{a}>0$, where $\Delta K=K_{1}-K_{1}^{e}+K_{2}-K_{2}^{e}$. Therefore, as long as $b_{2} \leq f_{1}\left(b_{1}\right) \equiv$ $\left(\left(v-c_{a}\right) / v-b_{1} K_{1}\right) /\left(K_{2}-b_{1} \Delta K\right)$. Let us define $\Gamma=\left\{\left(b_{1}, b_{2}\right) / b_{2} \leq f_{1}\left(b_{1}\right)\right\}$.

With ex ante agreement, and if both patentholders propose a pool that the developer accepts, each patentholder $i$ gets $-c_{i}+k_{i}^{p}\left(v-c_{a}\right)$ for $i=1,2$ and the developer earns $\left(1-k_{1}^{p}-k_{2}^{p}\right)\left(v-c_{a}\right)$. If only one of the patentholders proposes an ex ante agreement to the developer, the application can still infringe on the other patent. If it does infringe, an ex post licensing is needed to bring about the application. Thus, the patentholder $j$ who refuses the ex ante agreement, will bargain over the totality of the gain from the application. Hence, the payoff of $j$ will be $-c_{j}+b_{j} K_{j} v$ for $j=1,2$ and $j \neq i$. The surplus over which firm $i$ and the developer will ex ante bargain is thus $\left(1-b_{j} K_{j}\right) v-c_{a}$. Therefore, patentholder $i$ gets $-c_{i}+k_{i}\left(\left(1-b_{j} K_{j}\right) v-c_{a}\right)$ and the developer gets $\left(1-k_{i}\right)\left(\left(1-b_{j} K_{j}\right) v-c_{a}\right)$.

As before, at best, if both patentholders propose an ex ante agreement, the developer can earn $\left(1-k_{1}^{p}-k_{2}^{p}\right)\left(v-c_{a}\right)$ and, thus, as it is positive, the application will be brought about. However, if only one patentholder proposes an ex ante agreement, the developer will get (1$\left.k_{i}\right)\left(\left(1-b_{j} K_{j}\right) v-c_{a}\right)$ and, thus, the investment will be undertaken only if $\left(1-b_{j} K_{j}\right) v-c_{a}>0$.

The Nash equilibria we find are such that the patentholders form a patent pool when they have patents of very different breadths or, on the contrary, very broad patents. When both basic patents are very broad, the developer will decide to develop the application only under an ex ante agreement. Therefore, the application will only be brought about if a pool of patents is formed. On the other hand, a patentholder who has a very narrow patent is tempted to offer an ex ante agreement, while a patentholder with a very broad patent is tempted to wait for an $e x$ post agreement. However, the developer will not accept an ex ante agreement from the holder of the narrow patent. Therefore, the application will be developed only if a pool of patents is 
first introduced (see figure 1). For all of the other configurations of breadth, ex ante or ex post agreements can be achieved, but no pool of patents will be offered. For very small breadths, $\left(b_{1}, b_{2}\right) \in \Gamma$, ex post efficiency is achieved at the equilibrium. For intermediate values of breadth, one firm offers an ex ante agreement and the other firm does not.

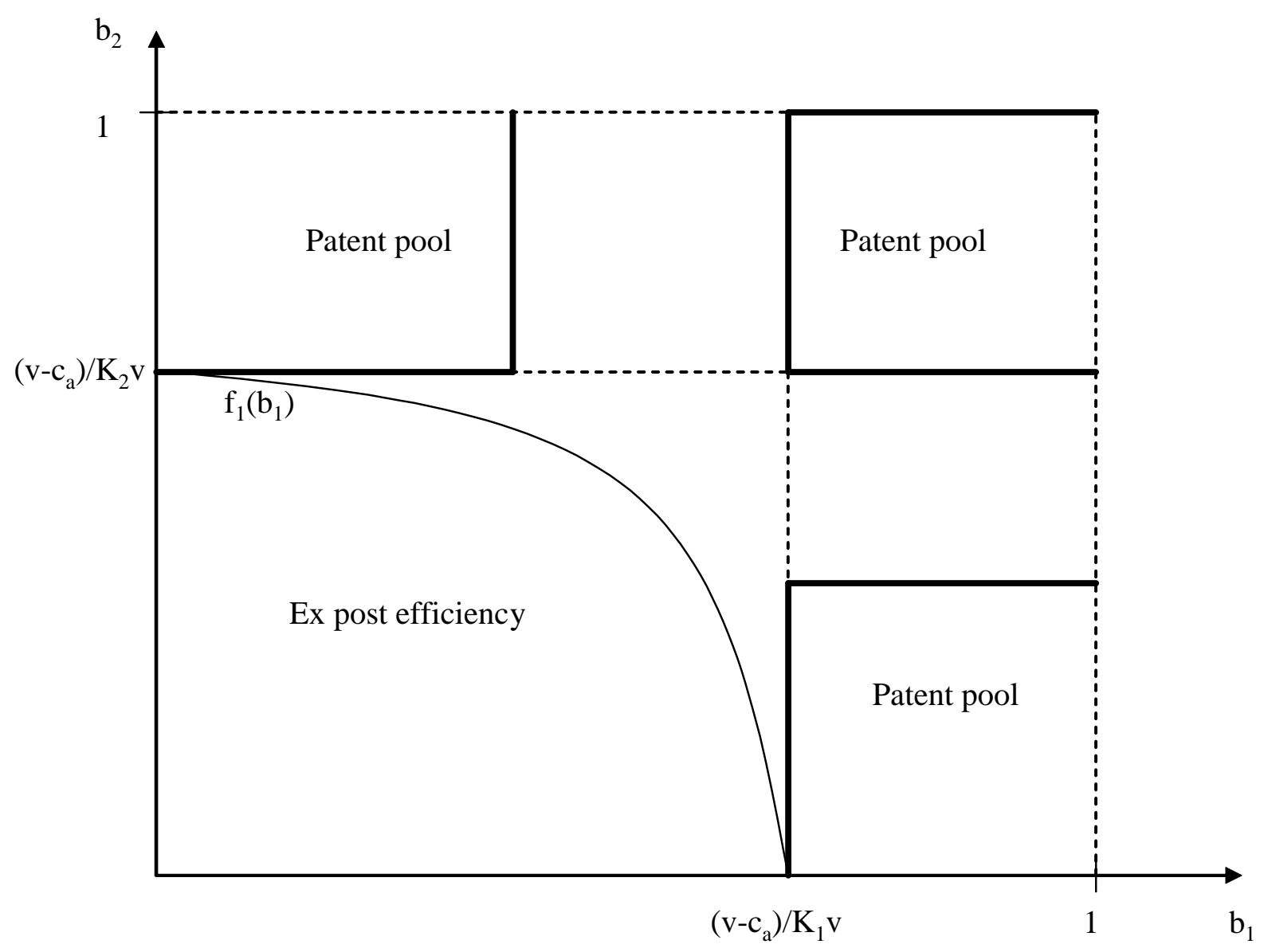

Figure 1: Patent pools

We summarize these findings in the following proposition.

Proposition 3 (pool of patents) Under assumptions (1)-(5), a patent pool is formed if:

1. the two patents are very broad;

2. one patent is very broad and the other patent is very narrow.

Proof. See appendix. 
It seems counterintuitive that patentholders with broad patents and, therefore, strong monopoly rights, have to consent to pool their patents. Although they have broad patents, they have to agree to share the development costs in order to also enjoy their monopoly rights. In this setting, absent a patent pool, patentholders with strong monopoly rights would not be able to enjoy those rights, as no application would be developed.

On the other hand, to better understand why pools may be formed with very different breadths, one can think of an alternative interpretation of $b_{i}$ that could be the ability of the innovators to litigate. Such ability arguably depends on the size and experience of the firms involved in the litigation process. Therefore, asymmetric equilibria may reflect a pool composed of very different firms: an inexperienced firm (e.g., a start-up) that seeks some protection from a bigger and more experienced firm.

However, basic innovators do not necessarily have the right incentive to ex ante invest in basic innovation. For very narrow patents, when an ex post agreement can be reached $\left(\left(b_{1}, b_{2}\right) \in \Gamma\right)$, basic innovators do not invest if $b_{i} \in\left[0, c_{i} / K_{i} v\right]$. Therefore, within this area, investment will occur only if $b_{i}>c_{i} / K_{i} v$.

For intermediate values of breadth, the basic innovator who proposes an ex ante agreement does not have enough incentive to invest. One of the basic innovators lacks the incentive if $b_{i} \in\left[\left(v-c_{a}\right) / K_{j} v-c_{i} / k_{i} K_{j} v,\left(v-c_{a}\right) / K_{i} v\right]$. In other words, if the breadth is too large within the considered interval, there will be no innovation, as one of the basic innovators lacks the incentive to develop the innovation that is needed to develop the application.

Therefore, an ex ante agreement may not be enough to rectify incentives when two basic innovators must decide whether or not to pool their patents. Indeed, each of them has an incentive to free-ride on the other. One of the basic innovators lets the other form an ex ante agreement with the developer, and then free-rides in the case of infringement. The broader the patent, the higher the probability of free-riding. However, if the patent is too broad, there is no investment.

Proposition 4 (incentives to invest) If there are two basic innovators, ex ante agreement restores incentives to develop an application, but may reduce the ex ante incentive to invest in the basic innovations.

If we compare this result with the one basic innovator case, because of the free-riding problem 
created by the possibility of letting the other basic innovator share the development costs, we have a situation of under-investment. Indeed, for the values of breadth where firms do not form a pool, but ex ante and ex post agreements occur, the incentive to develop the application is restored, but the incentive to do basic research is weakened. As a result, less innovation occurs.

\section{Extensions}

We now explore two extensions of the model. In the first one, we consider that in case of patent pool failure, each patentholder can independently offer an ex ante agreement. Second, we consider a sequential game instead of a simultaneous one, in which the first patentholder first offers a pool, and the second patentholder decides whether to join the pool or not.

\subsection{Patent Pool versus Individual Ex Ante Agreements}

We consider that in case of patent pool failure, each of the patentholders can independently offer an ex ante agreement. The timing of the game is now the following:

- First, the two patentholders decide simultaneously whether to pool their patents or not.

- In case of patent pool failure, each patentholder decides simultaneously to offer separate ex ante agreements to the developer.

- In case of ex ante agreements, the developer decides to accept or not the ex ante agreement, and to invest or not in the development of the application.

- In the absence of ex ante agreements, ex post efficiency must be achieved to bring about the application.

To solve this new game, we first solve the ex ante agreement subgame before solving the patent pool subgame. In fact, the resolution of the ex ante agreement subgame is identical to the one presented in the paper, except that the share of payoff of each patentholder is now $k_{i}^{a}$ for $i=1,2$ instead of $k_{i}^{p}$. Once we solve the ex ante agreement subgame, we simply solve the

patent pool game. If we make the realistic assumption that $k_{i}^{p}>k_{i}^{a}$, i.e., that the share of payoff that each patentholder will receive from being part of a pool is higher than the share of payoff each will get from offering independent ex ante agreements, the results are identical to 
those obtained in the previous section. Alternatively, it could be the case that it is cheaper to negotiate in a pool than separately. Therefore, in this simple model, because we do not explicitly determine the optimal share of payoff of each of the patentholders, offering patent licenses in a pool dominates offering separate licenses.

\subsection{Sequential Formation of a Pool}

We may also be concerned with the fact that pools in general are formed sequentially rather than simultaneously. One firm may decide to offer a pool with one patent, and another firm may decide to join the pool after its creation. In our setting, this change in the sequence of decisions does not affect our findings. Indeed, pools will emerge with the same characteristics as those we defined in proposition. This is again due to the fact that the shares of the payoff are exogenous. If the shares of the payoff were endogenous, the first firm would want to have the larger share, and we would also have to be more specific about the identity of the first patentholder that proposes a patent pool.

\section{Conclusion}

Patents play an important role in many industries (e.g., biotechnology), and the existence of too many property rights on basic innovations impacts follow-up applications. In a context where basic innovations have no value by themselves, but are fundamental to the development of an application, we show that basic innovators will tend to pool their patents when they have broad patents or when their patents are of very different breadth (one broad, one narrow). By doing so, they induce investment in applications that would not occur otherwise.

In this simple setting, all of the variables are exogenous, and the only decisions are on whether to invest and whether to pool. We do not consider any strategic choice of breadth, but, rather, we investigate all of the possible pools that will emerge depending on the different breadths. We also consider the share of profits as given in the case of agreement.

Our analysis of pools relies on an ex ante agreement motivated by the example given in the introduction, and on the fact that prior to doing research, innovators need to obtain a license in order to develop an application.

The problem with such ex ante agreements is that they bring antitrust concerns. Should 
we allow initial patentholders to reach ex ante agreements even though applications do not necessarily infringe on the initial patents? Evidence exists that the Department of Justice allows such ex ante agreements (patent pools) when patents are complements but not substitutes or rivals (see the Department of Justice's Antitrust Guidelines for the License of Intellectual Property).

One of our findings suggests that the broader the patent protection of both patents, the more likely a pool of patents will emerge. Thus, one may wonder if the emergence of patent pools that has been observed during recent years could be the result of a patent policy that allows for broad patents. However, we find that patent pools can be composed of one broad and one narrow patent as well.

From an antitrust standpoint, such agreements are less problematic since they do not result in a strong barrier to entry, but still foster and restore incentives to develop applications. 


\section{References}

[1] Aoki, R. and S. Nagaoka. "The Consortium Standard and Patent Pools," Working paper, $32(2004)$.

[2] Bessen, J. "Hold-Up and Licensing of Cumulative Innovations with Private Information," Economics Letters, 82:321-326 (2004).

[3] Buchanan, J. and Y. Yoon. "Symmetric Tragedies: Commons and Anticommons," Journal of Law and Economics, XLIII:1-13 (2000).

[4] Chang, H. "Patent Scope, Antitrust Policy and Cumulative Innovation," RAND Journal of Economics, 26:34-57 (1995).

[5] Denicolo, V. "Two-Stage Patent Races and Patent Policy," RAND Journal of Economics, $31: 488-501(2000)$.

[6] Gilbert, R. "Antitrust for Patent Pools: A Century of Policy Evolution," Stanford Technology Law Review (2004).

[7] Gilbert, R. and M. Katz. "Should Good Patents Come in Small Packages? A Welfare Analysis of Intellectual Property Bundling," International Journal of Industrial Organization, 24(5):931-952 (2006).

[8] Green, J. and S. Scotchmer. "On the Division of Profit in Sequential Innovation," RAND Journal of Economics, 26(1):20-33 (1995).

[9] Heller, M. and R. Eisenberg. "Can Patent Deter Innovations? The Anticommons in Biomedical Research," Science, 280:698-701 (1998).

[10] Klemperer, P. "How Broad Should the Scope of Patent Protection Be?," RAND Journal of Economics, 21:113-130 (1990).

[11] Layne-Farrar, A. and J. Lerner. "To Join or Not to Join: Examining Patent Pool Participation and Rent Sharing Rules," mimeo LECG and Harvard University (2006).

[12] Lerner, J. "The Importance of Patent Scope: An Empirical Analysis," RAND Journal of Economics, 25:319-333 (1994). 
[13] Lerner, J. and J. Tirole. "Efficient Patent Pools," American Economic Review, 94, no. 3:691-711 (2004).

[14] Lerner J., M. Strojwas and J. Tirole. "Cooperative Marketing Agreements Between Competitors: Evidence from Patent Pools," Harvard working paper (2003).

[15] Merger, R. and R. Nelson. "On Limiting or Encouraging Rivalry in Technical Progress: The Effect of Patent Scope Decisions," Journal of Economic Behavior and Organization, 25:1-24 (1994).

[16] Merges, R. "Institutions for Intellectual Property Transactions: The Case of Patent Pools," unpublished working paper, UC Berkeley (1999).

[17] O'Donoghue T, S. Scotchmer and J-J Thisse. "Patent Breadth, Patent Life, and the Pace of Technological Progress," Journal of Economics and Management Strategy, 7(1):1-32 (1998).

[18] Scotchmer, S. "Protecting Early Innovators: Should Second Generation Product Be Patentable?," RAND Journal of Economics, 27:322-331 (1996).

[19] Shapiro, C. "Navigating the Patent Thicket: Cross Licensing, Patent Pools, and StandardSetting," Innovation Policy and the Economy, A. Jaffe, J. Lerner and S. Stern, Eds., Vol. 1. Cambridge, MA: MIT press, 119-150 (2001). 


\section{Appendix}

\section{$\underline{\text { Proof of Proposition } 3}$}

i) Investment decision for firm $A$

If no ex ante agreements are offered, firm $A$ invests as long as $v\left(1-b_{1} K_{1}-b_{2} K_{2}+b_{1} b_{2} \Delta K\right)-$ $c_{a}>0$, where $\Delta K=K_{1}-K_{1}^{e}+K_{2}-K_{2}^{e}>0$ or, equivalently, if $b_{2} \leq f_{1}\left(b_{1}\right) \equiv\left(\left(v-c_{a}\right) / v-\right.$ $\left.b_{1} K_{1}\right) /\left(K_{2}-b_{1} \Delta K\right)$, where $f_{1}\left(b_{1}\right)$ is a decreasing and concave function.

If the two basic innovators offer a pool, firm $A$ always invests, as $\left(v-c_{a}\right)\left(1-k_{1}^{p}-k_{2}^{p}\right)>0$. On the other hand, if only firm 1 (respectively, firm 2) offers an ex ante agreement, but not firm 2 (respectively, firm 1), firm $A$ invests if $\left(1-k_{1}\right)\left(\left(1-b_{2} K_{2}\right) v-c_{a}\right)>0$ (respectively, $\left.\left(1-k_{2}\right)\left(\left(1-b_{1} K_{1}\right) v-c_{a}\right)>0\right)$ or, equivalently, if $b_{2} \leq\left(v-c_{a}\right) / K_{2} v$ (respectively, $b_{1} \leq$ $\left.\left(v-c_{a}\right) / K_{1} v\right)$.

ii) Simultaneous decisions to pool or not for firms 1 and 2

We now define the Nash equilibria when ex post efficiency is not achieved, i.e., $b_{2}>f_{1}\left(b_{1}\right)$.

In absence of any ex ante agreement, firm $A$ does not invest and, therefore the payoffs of firms 1 and 2 are $\Pi_{1}^{N, N}=-c_{1}$ and $\Pi_{2}^{N, N}=-c_{2}$ respectively. Let us represent a normal form of the game, where the payoffs of each firm depend on the decisions of each firm to pool or not.

\begin{tabular}{|l|l|l|}
\hline $1 \backslash 2$ & Pool & No Pool \\
\hline Pool & $\Pi_{1}^{P, P}, \Pi_{2}^{P, P}$ & $\Pi_{1}^{P, N}, \Pi_{2}^{P, N}$ \\
\hline No Pool & $\Pi_{1}^{N, P}, \Pi_{2}^{N, P}$ & $\Pi_{1}^{N, N}, \Pi_{2}^{N, N}$ \\
\hline
\end{tabular}

We first define the Nash equilibrium when firm $A$ invests when both firms decide to pool (Pool, Pool), and when only one of the basic innovators decides to pool, either (Pool, No Pool) or (No Pool, Pool) (i.e., for $b_{i} \leq\left(v-c_{a}\right) / K_{i} v$ for $\left.i=1,2\right)$. Therefore, the payoffs of firms 1 and 2 are the following.

$$
\begin{aligned}
& \Pi_{1}^{P, P}=-c_{1}+k_{1}^{p}\left(v-c_{a}\right) \\
& \Pi_{2}^{P, P}=-c_{2}+k_{2}^{p}\left(v-c_{a}\right)
\end{aligned}
$$




$$
\begin{aligned}
& \Pi_{1}^{P, N}=-c_{1}+k_{1}\left(\left(1-b_{2} K_{2}\right) v-c_{a}\right) \\
& \Pi_{2}^{P, N}=-c_{2}+b_{2} K_{2} v \\
& \Pi_{1}^{N, P}=-c_{1}+b_{1} K_{1} v \\
& \Pi_{2}^{N, P}=-c_{2}+k_{2}\left(\left(1-b_{1} K_{1}\right) v-c_{a}\right)
\end{aligned}
$$

If firm 2 (respectively, firm 1) chooses not to pool, firm 1 (respectively, firm 2) always chooses to pool, as $\Pi_{1}^{P, N}>\Pi_{1}^{N, N}$ (respectively, $\Pi_{2}^{N, P}>\Pi_{2}^{N, N}$ ) is always satisfied.

A pool cannot be an equilibrium, as both firms choose to pool if $b_{i} \leq k_{i}^{p}\left(v-c_{a}\right) / K_{i} v$, which is not possible.

Therefore, there exists an equilibrium in which firm 1 (respectively, firm 2) chooses to pool, whereas firm 2 (respectively, firm 1) does not pool for $b_{1} \leq k_{1}^{p}\left(v-c_{a}\right) / K_{1} v$ and $b_{2}>k_{2}^{p}(v-$ $\left.c_{a}\right) / K_{2} v$ (respectively, $b_{2} \leq k_{2}^{p}\left(v-c_{a}\right) / K_{2} v$ and $\left.b_{1}>k_{1}^{p}\left(v-c_{a}\right) / K_{1} v\right)$. For $b_{1}>k_{1}^{p}\left(v-c_{a}\right) / K_{1} v$ and $b_{2}>k_{2}^{p}\left(v-c_{a}\right) / K_{2} v$, different equilibria exist: either firm 1 chooses to pool and not firm 2, or vice versa, firm 2 decides to pool and not firm 1.

Second, we define the Nash equilibrium when firm $A$ invests when both firms decide to pool (Pool, Pool), and when only firm 1 decides to pool, but not when firm 2 decides to pool (Pool, No Pool) (i.e., for $b_{1} \leq\left(v-c_{a}\right) / K_{1} v$ and for $\left.b_{2}>\left(v-c_{a}\right) / K_{2} v\right)$. The payoffs of firms 1 and 2 are therefore identical to the previous ones, except for

$$
\begin{aligned}
& \Pi_{1}^{P, N}=-c_{1}, \\
& \Pi_{2}^{P, N}=-c_{2} .
\end{aligned}
$$

The Nash equilibrium is to $(\mathrm{Pool}, \mathrm{Pool})$ if $b_{1} \leq k_{1}^{p}\left(v-c_{a}\right) / K_{1} v$, and not to pool for firm 1 and to pool for firm 2 (No Pool, Pool), otherwise.

Similarly, for $b_{1}>\left(v-c_{a}\right) / K_{1} v$ and for $b_{2} \leq\left(v-c_{a}\right) / K_{2} v$, we find a Nash equilibrium in which both firms pool if $b_{2} \leq k_{2}^{p}\left(v-c_{a}\right) / K_{2} v$, and one in which firm 1 decides to pool but not firm 2 (Pool, No Pool).

Lastly, if firm $A$ only invests when a pool is offered, there is a unique equilibrium in which both firms decide to pool.

Hence, there exists a Nash equilibrium in which both firms decide to pool, i.e., (Pool, Pool) when 
i. $b_{1} \leq k_{1}^{p}\left(v-c_{a}\right) / K_{1} v$ and $b_{2}>\left(v-c_{a}\right) / K_{2} v$ (i.e., patent 1 is narrow and patent 2 is broad)

ii. $b_{2} \leq k_{2}^{p}\left(v-c_{a}\right) / K_{2} v$ and $b_{1}>\left(v-c_{a}\right) / K_{1} v$ (i.e., patent 1 is broad and patent 2 is narrow)

iii. $b_{i}>\left(v-c_{a}\right) / K_{i} v$ for $i=1,2$ (i.e., both patents are broad)

\begin{tabular}{|l|l|l|l|l|l|}
\hline & $\begin{array}{c}\text { Patent } \\
\text { Number }\end{array}$ & $\begin{array}{c}\text { Granting } \\
\text { Year }\end{array}$ & Assignee & $\begin{array}{l}\text { Related } \\
\text { Patents }\end{array}$ & $\begin{array}{l}\text { Number of } \\
\text { IPC classes }\end{array}$ \\
\hline 1 & $5,625,048$ & 1997 & Univ Cal & & 1 \\
\hline 2 & $5,777,079$ & 1998 & Univ Cal & 5625048 & 3 \\
\hline 3 & $5,804,387$ & 1998 & Stanford & & 3 \\
\hline 4 & $5,968,738$ & 1999 & Stanford & & 2 \\
\hline 5 & $5,994,077$ & 1999 & Stanford & 5804387 & 3 \\
\hline 6 & $6,054,321$ & 2000 & Univ Cal & continuation & 1 \\
\hline 7 & $6,066,476$ & 2000 & Univ Cal & 5625048 & 3 \\
\hline 8 & $6,077,707$ & 2000 & Univ Cal & continuation & 2 \\
\hline 9 & $6,090,919$ & 2000 & Stanford & 5804387 & 1 \\
\hline 10 & $6,124,128$ & 2000 & Univ Cal +other & & 2 \\
\hline 11 & $6,172,188$ & 2001 & Thastrup & & 3 \\
\hline
\end{tabular}

Table 1: patent pool GFP 


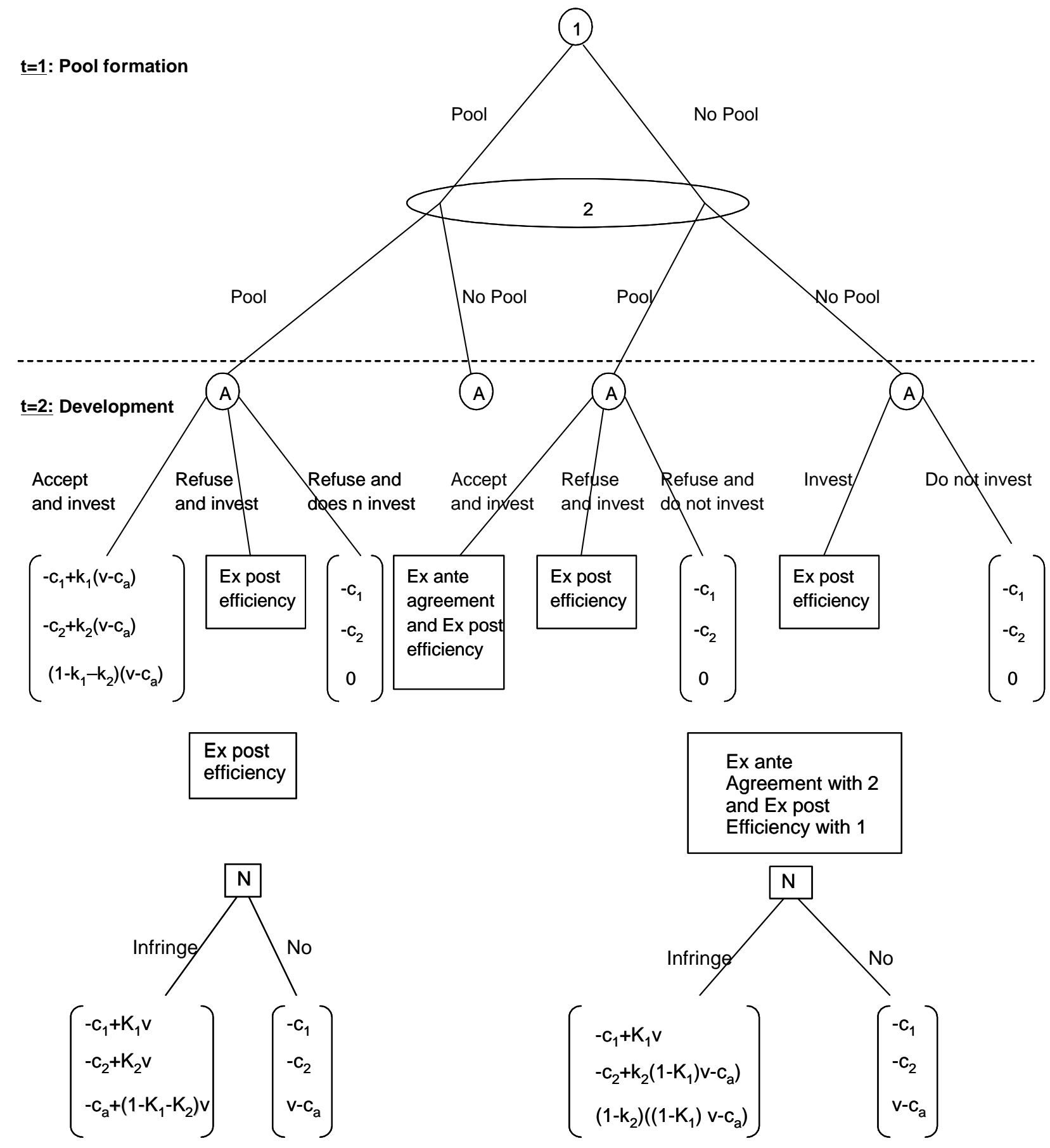

